\title{
Rheumatic Disease Autoantibodies in Patients with Autoimmune Thyroid Diseases
}

\author{
Renato Nisihara ${ }^{a}$ b Yasmine Gorczevski Pigosso ${ }^{b}$ Nathalia Prado ${ }^{b}$ \\ Shirley R.R. Utiyama ${ }^{a, c}$ Gisah A. De Carvalho ${ }^{d}$ Thelma L. Skare ${ }^{e}$ \\ a Laboratory of Immunopathology, Clinical Hospital, Federal University of Paraná, Curitiba, Brazil; \\ ${ }^{b}$ Department of Medicine, Positivo University, Curitiba, Brazil; ${ }^{c}$ Department of Clinical Analysis, \\ Federal University of Paraná, Curitiba, Brazil; 'Endocrinology Service, Clinical Hospital, Federal University of Paraná, \\ Curitiba, Brazil; ' Evangelic University Hospital of Curitiba, Curitiba, Brazil
}

\section{Significance of the Study}

- Patients with autoimmune thyroiditis showed positive antinuclear antibodies. In this study, we found patients with anti-Ro/SS-A positivity. In a disease with female predominance, this is very important, because autoantibodies may cross the placenta in pregnant women and cause neonatal lupus with a risk of congenital heart block, independently of the diagnosis of a background disease.

\section{Keywords}

Thyroiditis · Autoimmunity $\cdot$ Rheumatic diseases

\begin{abstract}
Background: Patients with autoimmune thyroid diseases (ATD) such as Graves' disease (GD) and Hashimoto thyroiditis (HT) may have non-organ specific autoantibodies such as antinuclear antibodies (ANA) and rheumatoid factor (RF). Aim: To study the prevalence of rheumatic autoantibodies in a group of ATD patients without known rheumatic diseases and to evaluate its association with the patients' epidemiological and treatment profiles. To follow positive nonorgan specific autoantibody-positive ATD individuals to investigate whether they will develop a rheumatic disorder. Methods: A sample of 154 ATD patients (70 HT and 84 GD;
\end{abstract}

mean age $45.3 \pm 14.2$ ) had determination of ANA by immunofluorescence, using hep-2 cells as substrate, extractable nuclear antigen profile by ELISA kits and RF by latex agglutination. Epidemiological and treatment profiles were obtained through chart review. These patients were followed for the mean period of 5 years, between 2010 and 2015 . Results: Positive ANA was found in 17.5\% (27/154) of the patients: anti-Ro/SS-A in 4/154 (2.5\%); anti-RNP in 4/154 (2.5\%), and anti-La/SS-B in 3/154 (1.9\%). None had anti-Sm antibodies. RF was detected in 12/154 (7.7\%) of ATD patients and was more common in older individuals ( $p=$ 0.007). There was a positive association between the presence of RF and ANA ( $p=0.03$; OR 3.89; 95\% Cl 1.1-13.3). None of the patients with positive autoantibodies developed clinical rheumatic diseases during the period of observation. Conclusion: We found rheumatic autoantibodies in

\section{KARGER}

E-Mail karger@karger.com www.karger.com/mpp
(C) 2018 The Author(s)

Published by S. Karger AG, Basel

Karger
Open access

This is an Open Access article licensed under the Creative Commons Attribution-NonCommercial-4.0 International License (CC BY-NC) (http://www.karger.com/Services/OpenAccessLicense), applicable to the online version of the article only. Usage and distribution for commercial purposes requires written permission.
Dr. Renato Nisihara

Laboratory of Immunopathology

Clinical Hospital, Federal University of Paraná

Rua Padre Camargo 280, Curitiba 80060-240 (Brazil)

E-Mail renatonisihara @ gmail.com 
$17.5 \%$ of ATD patients without rheumatic diseases. None of them were associated with the appearance of clinical rheumatic disorder during the period of 5 years.

(c) 2018 The Author(s)

Published by S. Karger AG, Basel

\section{Introduction}

Autoimmune thyroid diseases (ATD) are among the most common autoimmune diseases in humans and are often described as the prototypic single-organ directed autoimmune disease [1]. They include disorders such as Graves' disease (GD) and chronic lymphocytic thyroiditis, also referred to as Hashimoto disease (HT) [1]. These 2 diseases have a considerable overlap in the clinical presentation [1]. In these disorders, several autoantibodies against thyroid antigens such as thyroid peroxidase antibody, thyroglobulin antibody, and anti-TSH-receptor antibody are identified. In addition, non-organ specific autoantibodies such as antinuclear antibodies (ANA) and rheumatoid factor (RF), considered to be the hallmark of rheumatic diseases, may be present [2].

ATD are frequently seen in association with rheumatic diseases such as rheumatoid arthritis (RA), systemic lupus erythematosus (SLE), and Sjögren's syndrome (SS) [3]. Therefore, finding an autoantibody such as ANA or RF in an ATD patient may warrant further investigations. The differential diagnosis is further complicated by the fact that individuals with ATDs may have articular complaints [4].

ANA and RF are not specific for rheumatic diseases. A wide range of drug-induced, infectious and neoplastic situations may have these autoantibodies without any special significance [5]. When they also appear in other autoimmune non-rheumatic syndromes there is always a question of whether these autoantibodies are merely a serological finding or whether they are markers of an associated preclinical rheumatic disorder. It is well known that ANA and RF may predate the appearance of SLE and RA, respectively, for many years [6, 7]. In this prospective study, we determined the frequency of ANA and RF in a cohort of patients with ATD as well as the development of rheumatologic disease over a 5 -year period.

\section{Methods}

This study was approved by the Local Committee of Ethics in Research and all participants signed a written consent. It included 154 patients with ATD (70 HT and $84 \mathrm{GD})$. This is a sample that comprised all ATD patients from a single Endocrinology Outpatient Clinic from a tertiary hospital, that came for regular consultation during the year 2010 and that were included according to appointment order and willingness to participate in the study. Patients with a previous diagnosis of rheumatic disorders were excluded. HT was defined based on the presence of thyroid autoantibodies more than 2 times the upper normal value and thyroid ultrasound evaluation showing reduced echogenicity compatible with thyroiditis, with or without hypothyroidism. GD was defined by clinical symptoms and laboratorial tests (TSH and free T4) of hyperthyroidism. Treatment for thyroid disease was required in $92.2 \%$ of these patients.

All subjects completed a structured questionnaire for epidemiologic data, presence of arthralgias, and current medical treatment. TSH and free T4 were measured by chemiluminescence assays; normal TSH value varied between 0.3 and $4.0 \mathrm{mIU} / \mathrm{L}$ and free thyroxine between 4.5 and $12 \mu \mathrm{g} / \mathrm{dL}$.

Ten $\mathrm{mL}$ of venous blood were drawn, aliquoted, and preserved at $-80^{\circ} \mathrm{C}$ until ANA and RF tests were done. All the samples were screened for ANA by indirect immunofluorescence on hep- 2 cells, using a commercially available kit ANA hep-2 (Wama Diagnóstica, São Paulo, Brazil), as recommended by the manufacturer. A titer of 1:80 or higher was considered to indicate ANA positivity. The fluorescence patterns were interpreted as fine speckled, coarse speckled, homogeneous, peripheral, centromeric, nucleolar, and cytoplasmic patterns.

Only samples with positive ANA tests were assessed by ELISA for antibodies against extractible nuclear antigens (ENA; SS-A/ Ro, SS-B/La, Sm, RNP, Jo-1 and Scl-70), using individual ENA kit (Orgentec ${ }^{\circledR}$, Mainz, Germany) for detection and confirmation of the test. The cut-off level was set at $10 \mathrm{U} / \mathrm{mL}$, as recommended by the manufacturer.

All the samples were also tested to IgM-RF, measured by latex agglutination assay (BioSystems, S.A., Barcelona, Spain). Values $\geq 8 \mathrm{UI} / \mathrm{mL}$ were considered positive, as recommended by the manufacturer.

After data collection, ATD patients were clinically followed every 6 months for the development of any rheumatic disease for the period between 2010 and 2015 .

The results were collected in frequency and contingency tables. Comparison of nominal data was done by Fisher's exact test and of numerical data by Mann-Whitney (non-parametric data) and unpaired $t$ test (parametric data). The adopted significance was $5 \%$.

\section{Results}

\section{Description of Data}

Table 1 shows the main characteristics of the ATD population studied. In the control group, $90 \%$ were females $(p=0.94)$ and the mean age was $47.2 \pm 12.3$ years $(p=0.11)$. In this sample, the median TSH was of $1.83 \mathrm{mIU} / \mathrm{L}$ (range $0.003-98.0 \mathrm{mIU} / \mathrm{L}$ ) and the value of median-free T4 was of $1.23 \mu \mathrm{g} / \mathrm{dL}$ (range 0.4-3.15 $\mu \mathrm{g} / \mathrm{dL})$.
Rheumatic Autoantibodies in

Autoimmune Thyroiditis
Med Princ Pract 2018;27:332-336

DOI: $10.1159 / 000490569$ 
Table 1. Clinical and demographic data of autoimmune thyroid disease (ATD) patients $(n=154)$

\begin{tabular}{lc}
\hline Gender, female, $n(\%)$ & $139(90.2)$ \\
Age, years, mean \pm SD & $45.3 \pm 14.21$ \\
Ethnic background, $n(\%)$ & \\
$\quad$ Caucasian & $118(75.5)$ \\
Afro-descendants & $35(22.7)$ \\
Asiatic & $1(0.6)$ \\
Tobacco exposure, $n(\%)$ & $46(29.8)$ \\
Alcohol ingesting, $n(\%)$ & $6(3.8)$ \\
Graves/Hashimoto, $n(\%)$ & $84(54.5) / 70(45.4)$ \\
Treatment & $127(82.4)$ \\
Thyroid replacement, $n(\%)$ & \\
Thyroid replacement, & $0.31-4.42(1.65 \pm 0.71)$ \\
$\quad$ dose, $\mu$ g/kg/day, mean \pm SD & $12(7.7)$ \\
Tapazole, $n(\%)$ & $3(1.9)$ \\
Propylthiouracil, $n(\%)$ & $12(7.7)$ \\
None, $n(\%)$ & \\
\hline
\end{tabular}

ANA was present in 27/154 (17.5\%) patients, with titers from $1 / 80$ to $1 / 320$. In the ANA-positive patients, $14 / 27$ (51.8\%) had dense fine speckled pattern and $13 / 27$ (48.1\%) had coarse/fine speckled pattern. The study of ENA profile revealed that in the sample of ANA-positive patients, 4/27 (14.8\%) were anti-RNP positive; $4 / 27(14.8 \%)$ were anti-Ro/SS-A positive and $3 / 27(11.1 \%)$ presents anti-La/SS-B positive. All anti-La/SS-B positive patients were also positive for anti-Ro/SS-A. Anti-Sm antibody was not detected. AntiRo/SS-A and anti-RNP were both present in $4 / 154$ (2.5\%) and anti-La/SS-B in 3/154 (1.9\%). All but one ANA-positive patient were females. Rheumatoid factor was found in $12 / 154(7.7 \%)$ of ATD patients, in titers ranging from 8 to $1,280 \mathrm{UI} / \mathrm{mL}$.

All patients with ANA, ENA or RF positive tests were followed every 6 months for the mean period of 5 years, and none of these patients developed rheumatic disorders.

\section{Comparison of Autoantibody-Positive and-Negative Patients}

Table 2 shows the comparisons between subjects who tested positive and negative for either ANA or RF. ANA-positive patients had also more positive RF than those ANA-negative (18.5 vs. $5.5 \%$; $p=0.03$; OR 3.89; 95\% CI 1.13-13.39). Subjects with positive ANA were more likely to have positive RF compared to ANA-negative subjects. Those with RF positivity were older and were more likely to be smokers. Similar findings were also observed in patients with GD (Table 3).

\section{Discussion}

In our ATD sample, a prevalence of $17.5 \%$ ANA positivity was found. A previous study by Lazurova et al. [8] showed a higher prevalence of ANA (45\%), in an ATD sample with mainly HT ( $80 \%$ of their sample); Segni et al. [2] found a prevalence of $71 \%$ of ANA positivity in children with ATD, of which $92 \%$ had HT. Our results are lower than those previously described; however, our sample had a high incidence of GD (more than half of the sample). We took the precaution of excluding patients with prior diagnosis of rheumatic diseases that are considered to be more common in ATD patients and could cause positivity for this autoantibody.

It is worthwhile to note that almost half of the positive sample had a dense fine speckled pattern. ANA with dense fine speckled pattern (DFS70) results from autoantibodies binding to the ubiquitously expressed protein called lens epithelium-derived growth factor or p75 or psip1 gene product. This antibody is frequently found in normal population (up to $22 \%$ ), lacks association with a specific disease group and has a negative relationship with systemic autoimmune rheumatic diseases, even when in high titers $[9,10]$. On the contrary, in the other half of ANA-positive patients the pattern was fine or coarse speckled and about $15 \%$ of them were positive for anti-Ro/SS-A. Morita et al. [11] did not find anti-Ro/SS-A in their 50 patients with autoimmune thyroid disease, but Tektonidou et al. [12] found a prevalence of $10 \%$ of anti-Ro/SS-A positivity, and Elnady et al. [13], a positivity of $14.8 \%$ in their sample. Finding of anti-Ro/SS-A positivity in a disease with female predominance is very important, as this autoantibody may cross the placenta barrier in pregnant women and cause neonatal lupus with a risk of congenital heart block, independently of the diagnosis of a background disease [14]. Most mothers of babies born with neonatal lupus do not have SLE or another autoimmune disease, just the autoantibody [15]. Neonatal lupus accounts for $90-95 \%$ of cases of congenital heart block occurring in utero or in the neonatal period $[14,15]$. As this is a serious situation that may be prevented by glucocorticoid administration to the mother [14], it would be interesting to propose ANA screening (and further search for anti-Ro/SS-A) in ATD patients who became pregnant, to avoid this complication. In our study, all anti-Ro-positive patients were females.

No patient with ATD and positive ANA developed rheumatologic disease during the 5 years of observation. 
Table 2. Comparison of ATD patients according to ANA or RF positivity

\begin{tabular}{|c|c|c|c|c|c|c|}
\hline Age, years, mean \pm SD & $49.3 \pm 12.6$ & $44.5 \pm 14.4$ & 0.16 & $55.8 \pm 14.5$ & $44.4 \pm 13.8$ & 0.007 \\
\hline Caucasian ethnic background, $n(\%)$ & $20(74)$ & $98(77.1)$ & 0.82 & $10(83.3)$ & $108(76.0)$ & 0.83 \\
\hline Graves/Hashimoto, $n$ & $13 / 14$ & $71 / 56$ & 0.46 & $8 / 4$ & $76 / 66$ & 0.54 \\
\hline Smokers, $n(\%)$ & $5(18.5)$ & $22(17.3)$ & 0.88 & $5-41.6$ & $22-15.4$ & $0.03^{\#}$ \\
\hline users, $n(\%)$ & $3(11.1)$ & $12(9.4)$ & 1.00 & $2(16.1)$ & $13(9.1)$ & 0.33 \\
\hline Daily $\mathrm{T} 4$ dose, $\mu \mathrm{g} / \mathrm{kg}$, mean $\pm \mathrm{SD}$ & $1.55 \pm 0.65$ & $1.67 \pm 0.73$ & 0.91 & $1.48 \pm 0.31$ & $1.66 \pm 0.73$ & 0.70 \\
\hline
\end{tabular}

Value between brackets = interquartile range. ${ }^{\#}$ OR 3.8; 95\% CI 1.1-13.3.

$n$, number; ATD, autoimmune thyroid disease; ANA, antinuclear antibody; RF, rheumatoid factor.

Table 3. Comparison of HT and GD patients according to ANA or RF positivity

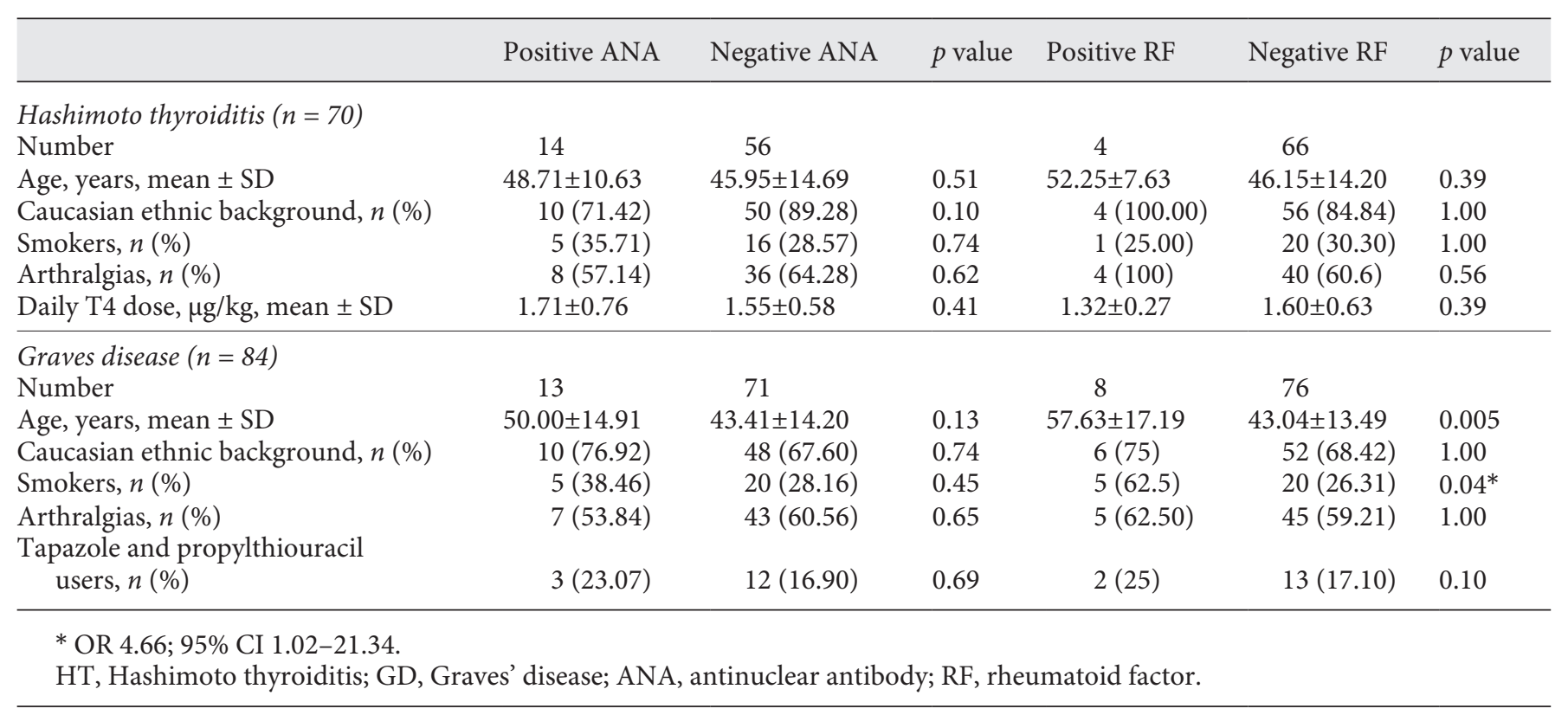

A study on 168 ATD patients from Greece identified $35 \%$ as ANA-positive, of which $9 \%$ of them fulfilled the criteria for Sjögrens' diagnosis and 3.4\% for SLE [12]. However, this was a study with a different design from the present study, as these authors did not exclude patients with prior diagnosis of rheumatic disease from their sample. In contrast to our findings, Elnady et al. [13] followed HT patients with non-organ specific autoantibodies for 2 years and found that almost $1 / 3$ developed rheumatic disease; anti-dsDNA and RF were the most significant predictors of disease occurrence. Differences in the ethnic background of the studied sample may explain some of these discrepancies as both ATD and rheumatic diseases are influenced by genes such as MHC class 2, CTLA4, and PTPN22 [16]. On the contrary, corroborating our findings, a study by Petri et al. [17], on 26 patients with Hashimoto's thyroiditis and 26 patients with GD detected $46.2 \%$ ANA positivity but could not associate this autoantibody to subclinical systemic autoimmune disease.

The presence of RF was detected in $7.7 \%$ of our subjects and showed a positive association with older age and cigarette smoking. Association of this autoantibody with older age was also observed in the normal population [18] 
and in RA patients [19]. Likewise, smoking is considered not only to be linked with RF-positive RA, but also to influence the immune system, leading to increased production of IgM and IgA RF in non-rheumatic individuals [20].

An interesting observation in this study is the association between the presence of ANA and RF. Some researchers suggest that the presence of non-organ specific autoantibodies may indicate an accelerated production of polyclonal autoantibodies by immune cells [21]. Our findings support this suggestion.

A limitation to our study is that it included very few male subjects. So, our findings cannot be generalized to men with ATD and positive ANA or RF.

\section{Conclusion}

We found a high prevalence of ANA, but not RF autoantibodies, in our population of ATD patients. In addition, none of these patients developed rheumatic disease during the 5-year follow-up period. Further studies are needed to understand the clinical value of finding antiRo/SS-A autoantibodies in a female ATD patient that considers pregnancy.

\section{Disclosure Statement}

All the authors declare that they have no conflict of interest.

\section{References}

1 Tagoe CE, Zezon A, Khattri S: Rheumatic manifestations of autoimmune thyroid disease: the other autoimmune disease. J Rheumatol 2012;39:1125-1129.

2 Segni M, Pucarelli I, Truglia S, Turriziani I, Serafinelli C, Conti F: High prevalence of antinuclear antibodies in children with thyroid autoimmunity. J Immunol Res 2014;2014:150239.

3 Punzi L, Betterle C: Chronic autoimmune thyroiditis and rheumatic manifestations. Joint Bone Spine 2004;71:275-283.

4 Tagoe C: Rheumatic symptoms in autoimmune thyroiditis. Curr Rheumatol Rep 2015; 17:5.

5 Birtane M, Yavuz S, Taștekin N: Laboratory evaluation in rheumatic diseases. World $\mathrm{J}$ Methodol 2017;7:1-8.

6 Arbuckle MR, McClain MT, Rubertone MV, Scofield RH, Dennis GJ, James JA, et al: Development of autoantibodies before the clinical onset of systemic lupus erythematosus. N Engl J Med 2003;349:1526-1533.

7 Rantapää-Dahlqvist S: What happens before the onset of rheumatoid arthritis? Curr Opin Rheumatol 2009;21:272-278.

8 Lazurova I, Benhatchi K, Rovensky J, Kozakova $\mathrm{D}$, Wagnerova $\mathrm{H}$, Tajtakova $\mathrm{M}$, et al: Autoimmune thyroid disease and autoimmune rheumatic disorders: a two-sided analysis. Ann NY Acad Sci 2009;1173:211-216.
9 Malyavantham K, Suresh L: Analysis of DFS70 pattern and impact on ANA screening using a novel HEp-2 ELITE/DFS70 knockout substrate. Auto Immun Highlights 2017;8:3.

10 Conrad K, Röber N, Andrade LE, Mahler M: The clinical relevance of anti-DFS70 autoantibodies. Clin Rev Allergy Immunol 2017;52: 202-216.

11 Morita S, Arima T, Matsuda M: Prevalence of nonthyroid specific autoantibodies in autoimmune thyroid diseases. J Clin Endocrinol Metab 1995;80:1203-1206.

12 Tektonidou MG, Anapliotou M, Vlachoyiannopoulos P, Moutsopoulos HM: Presence of systemic autoimmune disorders in patients with autoimmune thyroid diseases. Ann Rheum Dis 2004;63:1159-11561.

13 Elnady BM, Kamal NM, Shaker RH, Soliman AF, Hasan WA, Alghamdi HA, et al: Prevalence and clinical significance of nonorgan specific antibodies in patients with autoimmune thyroiditis as predictor markers for rheumatic diseases. Medicine (Baltimore) 2016;95:e4336

14 Johnson B: Overview of neonatal lupus. J Pediatr Health Care 2014;28:331-341.

15 Lee LA: Transient autoimmunity related to maternal autoantibodies: neonatal lupus. Autoimmun Rev 2005;4:207-213.
16 Taketomo Y, Noso S, Babaya N, Hiromine Y, Ito $\mathrm{H}$, Kanto K, et al: Common phenotype and different non-HLA genes in Graves' disease and alopecia areata. Hum Immunol 2017;78: 185-189.

17 Petri M, Karlson EW, Cooper DS, Ladenson PW: Autoantibody tests in autoimmune thyroid disease: a case-control study. J Rheumatol 1991;18:1529-1531.

18 Nisihara R, Kubis MM, Rodrigues PC, Skare $\mathrm{T}$, Mocelin V, Utiyama S: Antinuclear antibodies and rheumatoid factor positivity in healthy elderly adults: a cross-sectional study in 336 individuals. J Am Geriatr Soc 2013;61: 2044-2046.

19 Othman MA, Ghazali WS, Yahya NK, Wong KK: Correlation of demographic and clinical characteristics with rheumatoid factor seropositivity in rheumatoid arthritis patients. Malays J Med Sci 2016;23:5259.

20 Jonsson T, Thorsteinsson J, Valdimarsson H: Does smoking stimulate rheumatoid factor production in non-rheumatic individuals? APMIS 1998;106:970-974.

21 Huang CN, Hsu TC, Chou HH, Tsay GJ: Anti-nuclear antibody, anti-DNA, and aCL in Graves' disease patients treated with propyluracil or methimazole. Lupus 2004;13:450454 